\title{
Predicting Secure Detention Placement for African-American Juvenile Offenders: Addressing the Disproportionate Minority Confinement Problem
}

\author{
Christopher A. Mallett \\ Cleveland State University, c.a.mallett@csuohio.edu \\ Patricia A. Stoddard Dare \\ Cleveland State University, p.stoddarddare@csuohio.edu
}

Follow this and additional works at: https://engagedscholarship.csuohio.edu/clsowo_facpub

Part of the Race and Ethnicity Commons, Social Control, Law, Crime, and Deviance Commons, and the Social Work Commons

How does access to this work benefit you? Let us know!

\section{Publisher's Statement}

This is an Author's Original Manuscript of an article published by Taylor \& Francis Group in Journal of Ethnicity in Criminal Justice on April-June 2010 available online:

http://www.tandfonline.com/10.1080/15377931003761011

\section{Recommended Citation}

Mallett, Christopher A. and Stoddard Dare, Patricia A., "Predicting Secure Detention Placement for AfricanAmerican Juvenile Offenders: Addressing the Disproportionate Minority Confinement Problem" (2010). Social Work Faculty Publications. 8. https://engagedscholarship.csuohio.edu/clsowo_facpub/8

This Article is brought to you for free and open access by the School of Social Work at EngagedScholarship@CSU. It has been accepted for inclusion in Social Work Faculty Publications by an authorized administrator of EngagedScholarship@CSU. For more information, please contact library.es@csuohio.edu. 


\title{
Predicting Secure Detention Placement for African-American Juvenile Offenders: Addressing the Disproportionate Minority Confinement Problem
}

\author{
CHRISTOPHER A. MALLETT and PATRICIA STODDARD-DARE \\ School of Social Work, Cleveland State University, Cleveland, Obio, USA
}

\begin{abstract}
Disproportionate minority contact and confinement (DMC) are significant problems within the juvenile justice system in the United States. Minority youth are more often arrested, court referred, placed in locked facilities, and transferred to adult criminal courts. In fact, African American youth are 6 times more likely than White youth to experience a secure facility placement. Standardized risk assessments have been used, in part, to reduce these biased placement outcomes. The purpose of this article is to determine if DMC impacts secure detention placement even when a standardized risk assessment is used to determine youths' risks and needs in 1 Midwest county's juvenile court population over a 17-month time frame. Multivariate binary logistic regression results indicated and confirmed that African American youth were 2 times more likely to receive secure detention center placement than non-African American youth even when a standardized risk assessment was used. Practical applications and recommendations are set forth.
\end{abstract}

KEYTERMS Disproportionate minority confinement, secure detention, juvenile offenders, African American, risk assessment

Address correspondence to Christopher A. Mallett, School of Social Work, Cleveland State University, 2121 Euclid Avenue, \#CB324, Cleveland, OH 44115-2214, USA. E-mail: c.a.mallett@ csuohio.edu 


\section{INTRODUCTION}

\section{Disproportionate Minority Contact}

Disproportionate minority contact (DMC) within the United States' juvenile justice system is not new. The phenomenon has been documented within criminology literature for decades and has been a prioritized focus for federal and state policymakers since the 1990s (President's Commission, 1967; Puzzanchera \& Adams, 2008). It is generally agreed that minority youth, especially African Americans, are found disproportionately at the point of arrest, detainment pending investigation, juvenile court referral (16\% of population but make up 30\% of referrals; National Council on Crime and Delinquency, 2007), case petitioning, secure confinement, and transfers to adult criminal court (58\% of youth admitted to state adult prisons; Puzzanchera, Adams, \& Snyder, 2008). In addition, minority youth make up only one third of the population but account for two thirds of youth in long-term juvenile justice facilities and are more likely to be incarcerated than nonminority youths for the same types of offenses (Hoyt et al., 2001; Kempf-Leonard, 2007; National Council on Crime and Delinquency, 2007; Poe-Yamagata \& Jones, 2000; Shelton, Neelum, \& Augarten, 2008).

In particular, an African American youth is six times more likely to be incarcerated (jails and detention facilities) compared to White youth (and held on average 61 days longer; Mauer \& King, 2007; National Council on Crime and Delinquency, 2007). The experience of detention makes it more likely they will continue to engage in delinquent behavior and may increase the odds that they recidivate (Holman \& Ziedenberg, 2006; Torres \& Ooyen, 2002), an outcome that perpetuates the disparity problem (Bishop, 2005). Also concerning is the underrepresentation of minority youth in cases that are diverted from the juvenile courts and those cases that come under probation supervision (National Council on Crime and Delinquency, 2007; Puzzanchera et al., 2008). This may be correlated to the arrest disparities, whereby arrests of White youth have decreased 9\% from 2001 to 2006 but African American youth arrests have increased $7 \%$ during this same time period (Johnson, 2009).

Decisions throughout the juvenile justice system are interrelated and can affect DMC in cumulative ways, with earlier decisions impacting later ones. Possible explanations, though without any clear consensus, for this DMC problem include youth socioeconomic status, youth family structure, different juvenile justice system processing, differing youth offenses, implicit or explicit system bias, racial inequality, and crime policies (Engen, Steen, \& Bridges, 2002; Kempf-Leonard, 2007; Olatunde \& Johnson, 2007; Sampson, Morenoff, \& Raudenbush, 2005). DMC explanations can be categorized into two areas-differential youth involvement with the system and differential selection by the juvenile justice system itself-but are most probably a function of both (Piquero, 2008). 


\section{Risk Assessment/Standardized Instruments}

One intervention that has been suggested to address this problem is the implementation and appropriate use of standardized assessments in an effort to identify and provide appropriate and consistent intervention decisions for court-referred youth (Piquero, 2008). Court personnel struggle with the judgment for each juvenile offender as to their dangerousness, blameworthiness, and future behavior, balanced with their benefit from different juvenile court interventions. At numerous points within the juvenile justice system-diversion, offense charge, secure detention prior to disposition, evaluations, dispositions-court professionals make these judgments, oftentimes based only on professional experience and intuition (Mulvey \& Iselin, 2008; Steen et al., 2005).

Further investigating the explanations for DMC is important in light of some recent findings that looked at juvenile justice system personnel. In one study, probation officers were found to be greatly influenced by race in assessing reoffending risk and sentence recommendations, with African American youth being viewed at much higher risk even after controlling for case and offender characteristics (Steen et al., 2005). In other studies, both African American and White police officers were found to view African American youth more negatively, expect higher recidivism rates, and endorse harsher punishments (Bridges \& Steen, 1998; Graham \& Lowery, 2004). Other researchers have looked at the arrest and detention decision points and found more race effects compared to the later petitioning and adjudication decision points (Engen et al., 2002).

These court personnel making decisions for juvenile offenders have historically relied on professional judgment to determine the appropriate disposition(s). These decisions often reflect a larger organizational perspective, referred to as a "working ideology" (Kelly, 1996) or "theory of the office" (Drass \& Spencer, 1987). Knowing that disproportionate minority contact results from cumulative decisions at numerous points, this influence could have broader impact as youth penetrate the juvenile justice system. In other words, "officials' perceptions then are a critical ... link in explaining the relationship between defendant characteristics (including race) and case dispositions" (Steen et al., 2005, p. 245). Using standardized instruments (including the Youth Level of Service/Case Management Inventory [Y-LSI] and the Massachusetts Youth Screening Instrument [MAYSI-2]) provides a more valid and consistent assessment and prediction (Mulvey \& Iselin, 2008; Rubin \& Babbie, 2008) for youth involved in the juvenile courts.

To summarize, African American youth are disproportionately represented at almost all stages of juvenile justice in the United States. Many theories exist as to why this is the case. There is an effort to use standardized instruments, which provide a certain level of reliability and validity, to decrease possible bias and increase appropriate referral at the earlier decision 
points in the juvenile justice system process. The intent is to maximize resources, reduce bias that may lead to overrepresentation, and provide the most appropriate treatment for offending youth.

\section{Research Question}

To further investigate these issues, the current study evaluated juvenile court outcomes in terms of youth placement after the youth have been referred for investigation and referral. The goal of this study was to determine if race impacts secure detention placement even after standardized instruments are used to best determine the youth's risk. Other relevant variables were also assessed as possible control or predictor variables including youths' alcohol and drug use, angry/irritable disposition, depressed/anxious mood, somatic complaints, suicidal ideation, traumatic experiences, gender, educational status, special education status, and level of offense. In order to measure this effect, a cohort of juvenile court referred youth in one Midwest county was studied. Findings from this study are useful for court personnel, and others working in law, social work, psychology, and public health as professionals increasingly utilize standardized assessment instruments in part to reduce DMC.

\section{METHODOLOGY}

\section{Population/Data Collection}

The study population included all arrested and/or charged youth from one mid-sized, Midwest county in the United States who were referred for investigation and possible juvenile court supervision over a 17 -month time period (January 2008 to May 2009). This population represented all the youth who were referred to the juvenile court's investigation and referral department during this time frame $(N=486)$. This department performs functions roughly equivalent to the presentence investigations in adult court systems. This population does not include all youth who were involved with the juvenile court at earlier decision points but a subset determined most at risk for more serious, or chronic, offending. Over $96 \%$ of the youth did come under court supervision. The juvenile court provided a dataset of deidentified records of these 486 youth along with and their demographic characteristics and court information.

The youth were predominately male $(77.7 \%, n=377 ; 0$ missing $)$ and White $(63.1 \%, n=303 ; n=5$ missing). Twenty-eight percent of youth ( $n=$ 89) have an individualized education plan (IEP), whereas $72 \%(n=229)$ do not ( $n=167$ missing). Nearly 90\% (valid percents reported) $(n=424)$ of youth were in school at the time of juvenile court involvement, whereas approximately $10 \%(n=52)$ were not in school $(n=167$ missing). The most 
serious offense on record was a felony for nearly 55\% $(n=252)$ of youth and a misdemeanor for $45 \%(n=207 ; n=26$ missing). Nearly $68 \%(n=$ 324) of the youth remained in their home while on juvenile court supervision and $32.6 \%$ ( $n=157 ; n=8$ missing) were supervised in the secure detention center.

\section{Measurement}

A total of six continuous and five dichotomous potential control/independent variables were measured using existing court record data. In order to measure the variables of interest the following procedures were used. Six MAYSI-2 subscales were used for this study. The MAYSI- 2 is a 52 -item standardized instrument with seven subscales used to identify mental health needs of youth. Court personnel administered this paper and pencil survey to the population of interest. This instrument requires a fifth-grade reading level and has been validated for use with offending youth. All variables using MAYSI-2 subscales were measured continuously. Alcohol/drug use was measured on a scale with a theoretical range from 0 to 8 . Higher scores indicate a youth exhibits recent negative consequences and characteristics associated with abuse/dependence and is more likely to be at risk for a substance use disorder. A youth's tendency toward anger and or irritability was measured using a MAYSI-2 subscale that has a theoretical range from 0 to 9. Higher scores on this scale indicate recent increased anger and irritability in mood, thinking, and behavior. Depression/anxiety was measured using a MAYSI-2 subscale with a theoretical range from 0 to 9 . Higher scores are an indication of anxiety or depression in the past few months. Somatic complaints were measured using a MAYSI-2 subscale with a theoretical range from 0 to 6 . Higher scores indicate recent bodily discomfort, which could be related to physical or psychological causes. Suicide ideation is measured using a MAYSI-2 subscale with a theoretical range from 0 to 5 . Higher scores indicate recent self-harm thoughts. Traumatic experiences measure youth's lifetime exposure to traumatic events. A commonly used MAYSI-2 subscale for thought disturbances was not used because it is valid for males only.

The MAYSI-2 has been deemed valid and reliable (internal consistency ranged from .61 to .86; test-retest reliability interclass correlations ranged from .73 to .89; concurrent validity established with similar scales; Grisso et al., 2001) for use with juvenile justice populations to screen for possible mental health needs.

Another standardized instrument, the Y-LSI was used to measure youths' needs and risk level. The Y-LSI is a 42-item checklist with eight subscales: offense history, family circumstances/parenting, education, peer relations, substance abuse, leisure/recreation, personality/behavior, and attitudes/orientation. The Y-LSI has demonstrated interrater reliability (interclass correlations ranged from .61 to.71), internal consistency (Chronbach's alpha 
ranged between .56 and .77 ), and predictive validity on recidivism measures (Schmidt, Hoge, \& Gomes, 2005). The theoretical range for this scale is 0 to 42, with higher scores indicating increased "criminogenic risk level and needs" (Schmidt et al., 2005, p. 329).

Other dichotomous variables that were measured include gender $(0=$ male, $1=$ female $)$, race $(0=$ not African American, $1=$ African American $)$, offense level $(0=$ misdemeanor, $1=$ felony $)$, education status $(0=$ not in school, $1=$ in school), and special education status $(0=$ no IEP, $1=$ IEP $)$. One dependent variable was measured, location of detention placement, which specifies whether the youth was referred back home or to the county detention center for supervision $(0=$ home, $1=$ secure detention $)$.

\section{Data Analysis}

In order to evaluate the research question, a series of logistic regression procedures were utilized. First, all variable pairs were evaluated in the bivariate mode to assess their fit within a multivariate model. The following independent and control variables were run individually with the dependent variable "location of detention placement" (home or secure detention): alcohol/drug use, angry/irritable, depressed/anxious, somatic complaints, suicidal ideation, traumatic experiences, Y-LSI assessment score, special education status, education status, offense level, gender, and race. Three variable pairs (alcohol/drug use, Y-LSI score, and race) were significant in the bivariate mode at less than or equal to .05 and were therefore entered into the multivariate model. Continuous variables were evaluated and determined to be linear in logit. Data were evaluated for missing data and outliers, and preliminary regression was run to calculate Mahalanobis distance and to examine multicollinearity among the predictors. Tolerance for all variables was greater than .1, and variance inflation factor (VIF) values were low as is desired. A moderate amount of collinearity was evidenced between Y-LSI and MAYSI scores as expected. Overall, multicollinearity was not a problem and no outliers were identified. Multivariate binary logistic regression was then performed $($ Indicator $=$ First, Method $=$ Enter $)$.

\section{RESULTS}

Results indicated that alcohol/drug use scores ranged from 0 to 8 in this population with a mean score of $1.27(S D=1.95)$, angry/irritable scores ranged from 0 to 9 in this population with a mean score of $3.37(S D=2.69)$, depressed/anxious scores ranged from 0 to 8 in this population with a mean score of $1.43(S D=1.65)$, somatic complaints scores ranged from 0 to 6 in this population with a mean score of $2.27(S D=1.83)$, suicide ideation scores ranged from 0 to 5 in this population with a mean score of $.43(S D=1.04)$, 
TABLE 1 Descriptive Data Findings

\begin{tabular}{|c|c|c|c|c|c|c|}
\hline Variable & $\begin{array}{l}\text { Number } \\
\text { of Youth }\end{array}$ & $\begin{array}{l}\text { Number } \\
\text { of Youth }\end{array}$ & $\mathrm{n}$ & $\begin{array}{l}\text { Missing } \\
\text { (No.) }\end{array}$ & Mean & $S D$ \\
\hline Race & $\begin{array}{l}\text { African } \\
\text { American } \\
177\end{array}$ & $\begin{array}{c}\text { Not African } \\
\text { American } \\
303\end{array}$ & 480 & 5 & - & - \\
\hline Gender & $\begin{array}{c}\text { Female } \\
108\end{array}$ & $\begin{array}{l}\text { Male } \\
337\end{array}$ & 485 & 0 & - & - \\
\hline Offense level & $\begin{array}{l}\text { Felony } \\
252\end{array}$ & $\begin{array}{c}\text { Misdemeanor } \\
207\end{array}$ & 459 & 26 & - & - \\
\hline Alcohol/drugs & - & - & 455 & 30 & 1.27 & 1.95 \\
\hline Detention placement & $\begin{array}{c}\text { Home } \\
324\end{array}$ & $\begin{array}{l}\text { Secure } \\
\text { detention } \\
157\end{array}$ & 481 & 4 & - & - \\
\hline Angry/irritable & - & - & 454 & 31 & 3.37 & 2.69 \\
\hline Depressed/anxious & - & - & 454 & 31 & 1.43 & 1.65 \\
\hline Somatic complaints & - & - & 455 & 30 & 2.27 & 1.83 \\
\hline Suicide ideation & - & - & 455 & 30 & .43 & 1.04 \\
\hline Traumatic experiences & - & - & 455 & 30 & 1.37 & 1.37 \\
\hline Y-LSI & - & - & 485 & 0 & 9.85 & 8.87 \\
\hline IEP & 89 Yes & $229 \mathrm{No}$ & 318 & 167 & - & - \\
\hline In school & 424 Yes & $52 \mathrm{No}$ & 476 & 9 & - & - \\
\hline
\end{tabular}

Note. IEP $=$ individualized education plan; Y-LSI $=$ Youth Level of Service/Case Management Inventory.

traumatic experiences ranged from 0 to 5 in this population with a mean of 1.37 ( $S D=1.37$ ), and Y-LSI risk assessment scores ranged from 0 to 34 in this population with a mean of 9.85 ( $S D=8.9$; see Table 1 for details).

Bivariate binary logistic regression procedures revealed the following predictor variables were not significant: angry/irritable, depressed/anxious, somatic complaints, suicide ideation, traumatic experiences, school, the presence of an IEP, offense level, and gender (see Table 2). Variables that were significant at less than .05 in the bivariate mode were included in the multivariate model. These variables included Y-LSI score, alcohol and drug indicator, and race.

Multivariate binary logistic regression results indicated the overall model fit $(-2$ Log likelihood [-2LL] $=520.39)$ of one predictor and two control variables was statistically reliable in distinguishing detention facility placement status, $X^{2}(3)=40.8, p=.000$. The model correctly classified $69.3 \%$ of cases (see regression coefficients in Table 3). Wald statistics indicated that race (specifically youth being African American), the MAYSI-2 alcohol and drug indicator score, and the Y-LSI score significantly predict placement. Specifically, these variables make placement into the detention center more likely. Indeed, an African American youth is two times more likely to be placed in secure detention compared to a non-African American youth.

Due in part to inflated -2LL values, but also to determine if there are points that unduly influenced the model, Cook's distance, DF Beta, and 
TABLE 2 Bivariate Binary Logistic Regression Findings

\begin{tabular}{|c|c|c|c|c|c|c|c|c|}
\hline Variable & B & SE & Wald & $d f$ & $p$ & $\begin{array}{l}\text { Odds } \\
\text { Ratio }\end{array}$ & $\begin{array}{l}95 \% \text { CI } \\
\text { Lower }\end{array}$ & $\begin{array}{l}95 \% \text { CI } \\
\text { Upper }\end{array}$ \\
\hline Race & .558 & .200 & 7.755 & 1 & $.005^{*}$ & 1.747 & 1.18 & 2.59 \\
\hline Gender & .271 & .229 & 1.403 & 1 & .236 & 1.311 & .837 & 2.054 \\
\hline Offense level & -.116 & .201 & .334 & 1 & .563 & .890 & .600 & 1.321 \\
\hline Alcohol/drugs & .155 & .050 & 9.558 & 1 & $.002^{*}$ & 1.168 & 1.058 & 1.288 \\
\hline Angry/irritable & .003 & .038 & .005 & 1 & .944 & 1.003 & .931 & 1.079 \\
\hline Depressed/anxious & .048 & .060 & .634 & 1 & .426 & 1.049 & .932 & 1.181 \\
\hline Somatic complaints & .009 & .055 & .026 & 1 & .871 & 1.009 & .906 & 1.124 \\
\hline Suicide ideation & -.033 & .098 & .113 & 1 & .736 & .967 & .798 & 1.173 \\
\hline Traumatic experiences & .015 & .073 & .040 & 1 & .842 & 1.015 & .879 & 1.172 \\
\hline Y-LSI & .049 & .011 & 19.203 & 1 & $.000^{*}$ & 1.051 & 1.028 & 1.074 \\
\hline IEP & -.138 & .270 & .262 & 1 & .609 & .871 & .513 & 1.479 \\
\hline In school & -.496 & .300 & 2.732 & 1 & .098 & .609 & .338 & 1.096 \\
\hline
\end{tabular}

Note. $\mathrm{CI}=$ confidence interval; IEP $=$ individualized education plan; Y-LSI $=$ Youth Level of Service/Case Management Inventory.

${ }^{*} p<.05$.

leverage statistics were evaluated. There were no unusually high values of the Cook's distance, all DF Beta values were less than 1, and leverage statistics were very close to their expected value meaning that there were no influential cases affecting the model. To determine if there were points that fit the model poorly, studentized residuals, standardized residuals, and deviance statistics were evaluated. All values were within an acceptable range.

\section{DISCUSSION}

It is well documented and of significant concern nationally and locally for policymakers and the juvenile courts that minorities, particularly African American youth, are disproportionately found in secure detention facilities (Kempf-Leonard, 2007; National Council on Crime and Delinquency, 2007; Poe-Yamagata \& Jones, 2000; Shelton et al., 2008). The purpose of this research study was to evaluate if DMC persists when a standardized instrument was used in the assessment phase of a group of serious, or chronic, youthful

TABLE 3 Multivariate Binary Logistic Regression Findings

\begin{tabular}{|c|c|c|c|c|c|c|c|c|}
\hline Variable & B & $\mathrm{SE}$ & Wald & $d f$ & $p$ & $\begin{array}{l}\text { Odds } \\
\text { Ratio }\end{array}$ & $\begin{array}{l}95 \% \mathrm{CI} \\
\text { Lower }\end{array}$ & $\begin{array}{l}95 \% \mathrm{CI} \\
\text { Upper }\end{array}$ \\
\hline Race & .697 & .221 & 9.939 & 1 & $.002 *$ & 2.00 & 1.302 & 3.097 \\
\hline Y-LSI & .052 & .012 & 18.274 & 1 & $.000^{*}$ & 1.054 & 1.029 & 1.079 \\
\hline Alcohol/drugs & .162 & .054 & 9.065 & 1 & $.003^{*}$ & 1.176 & 1.058 & 1.306 \\
\hline
\end{tabular}

Note. $\mathrm{CI}=$ confidence interval.

$* p<.05$. 
offenders. In order to evaluate this, a series of statistical tests were run. This data indicated that being African American is predictive of secure detention placement (versus home placement) even when controlling for standardized risk assessment scores. Indeed, African Americans were two times more likely to have secure detention placement compared to non-African Americans. This finding suggests that use of a standardized instrument such as the Y-LSI may reduce but does not eliminate DMC. In order to fully understand this issue it is useful to understand other factors that may predict or not predict secure detention placement.

In multivariate binary logistic regression, control variables can also be correctly interpreted as independent or predictor variables. As such, an additional finding from this study is identification of drug and alcohol problems (as measured by the MAYSI-2 subscale) as a significant predictor of secure detention placement. This finding has future application potential. This MAYSI-2 subscale is intended to identify youths who are using alcohol or drugs to a significant degree and who are at risk for substance abuse or dependency (Grisso et al., 2001). This indicator identified youth involved with the juvenile court that could be in need of and offered effective interventions to address their alcohol and/or drug risk, with the possibility of minimizing later detention outcomes. Specifically, because alcohol and drug issues increase youths' likelihood of having a secure detention placement, it makes sense to focus on prevention. The United States Office of Juvenile Justice and Delinquency Prevention recommends and supports the Center for the Study and Prevention of Violence's Blueprints Model. Three programs have been identified by this center as effective interventions-The Midwestern Prevention Project (MPP), The Life Skills Training Program, and the Project Towards No Drug Abuse (Center for the Study and Prevention of Violence, 2009).

Other findings of note from this research study include the independent variables tested that were not found to predict secure detention placement including angry/irritable disposition, depressed/anxious mood, somatic complaints, suicide ideation, traumatic experiences, educational status, special education status, offense level, and gender. Two of these variables found not to be predictive of secure detention were somewhat surprising-the offense level and special education disability status. Previous research has found that felony offenders, compared to misdemeanor offenders, are more likely to experience secure detention (Sickmund, 2009). Also, it is well documented that juvenile offenders with special education disabilities are disproportionately represented in detention facilities (up to 40\% of the facility populations; Mallett, 2008; National Center on Education, Disability, and Juvenile Justice, 2002; National Council on Disability, 2002). Here this was not the case and the explanation is not apparent. It may be that the combination of decisions and factors within the juvenile court processing (youth history, probation compliance, rehabilitation options, additional charges, multiple 
adjudications) that may impact decision making are not fully captured within this study's dataset. These are areas in need of further investigation. Similarly, it merits further review to determine why race and drug and alcohol problems were significant predictors of secure detention placement, whereas level of offense was not.

\section{Limitations}

This study has some limitations. First, secondary data were used to measure the variables of interest. As such, reliability of the data cannot be ensured. Similarly, because variables were measured using available existing court records, only a limited number of variables could be assessed. It could be that some important variables were not included in this analysis. A final limitation pertains to the population studied. Only a subset of the juvenile court population (those more severe or chronic offenders) from only one Midwest county were included limiting this study's external validity.

\section{Conclusion and Recommendations}

Although it does not entirely eliminate the problem, these findings support the continued use of standardized measurements to help address disproportionate minority contact concerns, with the possibility of decreasing African American youth placements into secure detention. The use of reliable and valid youth risk assessments within the juvenile justice system decision points to accurately determine level of need/supervision marks a significant step forward from past practice, though it is not the common practice in most juvenile courts (Mulvey \& Iselin, 2008; Steen et al., 2005). Although these youth assessments, when used, are at the initial court referral stages, there may be additional and expanded roles for these standardized tools, particularly if they help predict later juvenile justice system penetration. Future research investigations should include offense types or groupings (property, personal, drug, and status) and information on the earlier decision points in the juvenile justice process (e.g., arrest)—something that was not available here.

In sum, this study found that use of a standardized assessment instrument did not eliminate the overrepresentation of African American juvenile offenders in secure detention. Also, substance abuse prevention was noted as a possible strategy to reduce the need for secure detention. These findings are informative and allow some unique reviews of one decision point in the juvenile justice process and further the larger investigations into the disproportionate minority confinement problems.

\section{Next Research Steps}

Explicating and understanding these disproportionate minority contact and confinement problems are far from complete. In fact, the research processes 
and designs utilized to date mark only the beginning to finding solutions (Kempf-Leonard, 2007; Olatunde \& Johnson, 2007; Piquero, 2008). It is imperative not only to continue research aimed at uncovering reasons for disproportionate minority placement of youth into detention centers and locked facilities but also to expand the reviews across the juvenile justice system. Specifically, future research should investigate how earlier system processing points (contact, diversion, arrest, charges, adjudication, probation) may impact later decision making for youthful offenders even when standardized instruments are used. Also, it would be important to continue investigation of broader possible explanations for DMC, which may include implicit or explicit system bias, racial inequality, and crime policies.

\section{REFERENCES}

Bishop, D. (2005). The role of race and ethnicity in juvenile justice processing. In D. F. Hawkins \& K. Kempf-Leonard (eds.), Our children, their children: Confronting racial and ethnic differences in American juvenile justice (pp. 23-82). Chicago: University of Chicago Press.

Bridges, G., \& Steen, S. (1998). Racial disparities in official assessments of juvenile offenders: Attributional stereotypes as mediating mechanisms. American Sociological Review, 63, 554-570.

Center for the Study and Prevention of Violence. (2009). Institute of Behavioral Science, University of Colorado at Boulder. Retrieved July 14, 2009, from http://www.colorado.edu/cspv/

Drass, K., \& Spencer, J. (1987). Accounting for pre-sentencing recommendations: Typologies and probation officers' theory of office. Social Problems, 34, 277293.

Engen, R. L., Steen, S., \& Bridges, G. S. (2002). Racial disparities in the punishment of youth: A theoretical and empirical assessment of the literature. Social Problems, 49(2), 194-220.

Graham, S., \& Lowery, B. (2004). Priming unconscious racial stereotypes about adolescent offenders. Law \& Human Behavior, 28, 483-504.

Grisso, T., Barnum, R., Fletcher, K., Cauffman, E., \& Peuschold, D. (2001). Massachusetts Youth Screening Instrument for mental health needs of juvenile justice youths. Journal of the American Academy of Child and Adolescent Psychiatry, 40, 541-548.

Holman, B., \& Ziedenberg, J. (2006). The dangers of detention: The impact of incarcerating youth in detention and other secure congregate facilities. Baltimore: Annie E. Casey Foundation.

Hoyt, E. H., Schiraldi, V., Smith, B. B., \& Ziedenberg, J. (2001). Pathways to juvenile detention reform: Reducing racial disparities in juvenile detention. Baltimore: Annie E. Casey Foundation.

Johnson, L. (2009). Federal commitment offers welcomed support to local initiatives to promote racial and ethnic fairness. Retrieved July 10, 2009, from http://www.modelsforchange.net/index.html 
Kelly, D. (1996). General recommendations. In Deviant behavior: A text-reader in the sociology of Deviance (5th ed., pp. 1-9). New York: St. Martin's Press.

Kempf-Leonard, K. (2007). Minority youths and juvenile justice: Disproportionate minority contact after nearly 20 years of reform efforts. Youth Violence and Juvenile Justice, 5, 71-87.

Mallett, C. (2008). The disconnect between delinquent youths with mental health and special education disabilities and juvenile court outcomes. Corrections Compendium, 33(5), 1-23.

Mauer, M., \& King, R. S. (2007). Uneven justice: State rates of incarceration by race and ethnicity. Washington, DC: The Sentencing Project.

Mulvey, E. P., \& Iselin, A.R. (2008). Improving professional judgments of risk and amenability in juvenile justice. The Future of Children, 18(2), 35-57.

National Center on Education, Disability, and Juvenile Justice. (2002). Best and promising practices for short-term jails and detention centers. EDJJ Notes, 1, 2-3.

National Council on Crime and Delinquency. (2007). And justice for some: Differential treatment of youth of color in the justice system. Retrieved July 19, 2009, from http://www.buildingblocksforyouth.org/justiceforsome/jfs.pdf

National Council on Disability. (2002). National disability policy: A progress report, December. Retrieved July 9, 2009, from http://www.ncd.gov/newsroom/ publications/2003/progressreport_final.htm

Olatunde, C., \& Johnson, A. (2007). Disparity rules. Columbia Law Review, 107, $374-425$.

Piquero, A. R. (2008). Disproportionate minority contact. The Future of Children, 18(2), 59-79.

Poe-Yamagata, E., \& Jones, M. (2000). And justice for some, building blocks for youth. Retrieved July 12, 2009, from http://www.buildingblocksforyouth. org/justiceforsome/

President's Commission. (1967). The challenge of crime in a free society. Washington, DC: U.S. Government Printing Office.

Puzzanchera, C., \& Adams, B. (2008). National disproportionate minority contact databook. Developed by the National Center for Juvenile Justice for the Office of Juvenile Justice and Delinquency Prevention. Retrieved July 12, 2009, from http://ojjdp.ncjrs.gov/ojstatbb/dmcdb/

Puzzanchera, C., Adams, B., \& Snyder, H. (2008). An interpretation of the national DMC relative rate indices for juvenile justice system processing in 2005. National disproportionate minority contact databook. Prepared by the National Center for Juvenile Justice for the Office of Juvenile Justice and Delinquency Prevention. Retrieved July 12, 2009, from www.ojjdp.ncjrs.gov/ojstatbb/dmcd/

Rubin, A., \& Babbie, E. (2008). Research methods for social work. Pacific Grove, CA: Thomson/Brook/Cole.

Sampson, R., Morenoff, D., \& Raudenbush, S. (2005). Social anatomy of racial and ethnic disparities in violence. American Journal of Public Health, 95, 224232.

Schmidt, F., Hoge, R., \& Gomes, L. (2005). Reliability and validity analysis of the Youth Level of Service/Case Management Inventory. Criminal Justice and Behavior, 32, 329. 
Shelton, H. O., Neelum, A., \& Augarten, I. (2008). Critical condition: AfricanAmerican youth in the justice system. Campaign for Youth Justice. Retrieved July 19, 2009, from http://www.njjn.org/media/resources/public/resource_852.pdf

Sickmund, M. (2009). Delinquency cases in juvenile court, 2005. Washington, DC: Office of Juvenile Justice and Delinquency Prevention, Office of Justice Programs, Department of Justice.

Steen, S., Bond, C., Bridges, G., \& Kubrin, C. (2005). Explaining assessments of future risk: Race and attributes of juvenile offenders in presentencing reports. In D. F. Hawkins \& K. Kempf-Leonard (eds.), Our children, their children: Confronting racial and ethnic differences in American juvenile justice (pp. 245-269). Chicago: University of Chicago Press.

Torres, C., \& Ooyen, M. V. (2002). Briefing paper. Committee on Youth Services, New York. Retrieved July 18, 2009, from http://webdocs.nyccouncil. info/attachments/56612.htm?CFID $=1677675 \&$ CFTOKEN $=84562487$ 